\title{
The International Model Forest Network (IMFN): Elements of Success
}

\author{
by Peter Besseau1, ${ }^{1,4}$ Kafui Dansou ${ }^{2,4}$ and Frederick Johnson ${ }^{3,4}$
}

The International Model Forest Network (IMFN) was announced by Canada at the Rio (UNCED) Summit ten years ago to pilot outside of Canada a promising participatory field-level approach to sustainable forest management then being developed in Canada through its national model forest network. The IMFN has since grown from three sites in two countries (outside of Canada) in 1994 to 19 sites in 11 countries, in addition to numerous additional sites proposed and at early stages of development. Now with the successor event to Rio, the World Summit on Sustainable Development, about to take place in Johannesburg, South Africa, there is an appropriate milestone at which to pause and consider its evolution and growth. Among the elements of success attributed to the growth of the network the authors consider the nature of the approach itself as being an innovative re-formulation of widely shared management values, its flexibility across borders and ecosystems, and the support provided in its development by the Canadian Model Forest Network and other domestic and international partners. The article looks at similarities and differences between the international and Canadian applications of this approach and describes some of the lessons learned and difficulties met in applying the approach internationally.

\section{Key words: IMFNS, CMFN, International, Networking, Asia, Latin America}

Le Réseau international de forêts modèles (RIFM) a été dévoilé par le Canada lors du Sommet de Rio (CNUED) il y a dix ans dans le but d'implanter hors du Canada une approche prometteuse d'implication sur le terrain de l'aménagement forestier durable alors en développement au Canada par l'entremise de son réseau national de forêts modèles. Le RIFM est passé depuis de trois sites dans deux pays (hors Canada) en 1994 à 19 sites répartis dans 11 pays, en plus de nombreux sites proposés et en cours de développement initial. Avec l'événement qui suit Rio, le Sommet mondial sur le développement durable, qui aura lieu à Johannesburg en Afrique du Sud, nous sommes présentement à une étape cruciale au cours de laquelle il nous faut s'arrêter et prendre en considération l'évolution et la croissance du réseau. Parmi les éléments de succès attribués à la croissance du réseau, les auteurs considèrent la nature de l'approche en elle-même qui est une reformulation innovatrice des valeurs d'aménagement largement partagées, sa flexibilité malgré les frontières et les écosystèmes et l'appui accordé à son développement par le Réseau canadien des forêts modèles et ses autres partenaires domestiques et internationaux. Cet article examine les similitudes et les différences entre les applications internationales et canadiennes de cette approche et décrit certaines des leçons retenues et des difficultés rencontrées dans l'application de l'approche sur la scène internationale.

Mots-clés : RIFM, RCFM, international, Asie, Amérique latine

\section{Introduction}

The International Model Forest Network (IMFN) is a Canadian-sponsored initiative, supported by a Secretariat located with IDRC, in Ottawa ${ }^{5}$. The programme was announced by Canada at the United Nations Conference on Environment and Development (UNCED) in Rio de Janeiro ten years ago with a pledge of $\$ 10$ million from Canada's Green Plan to seed an international effort to

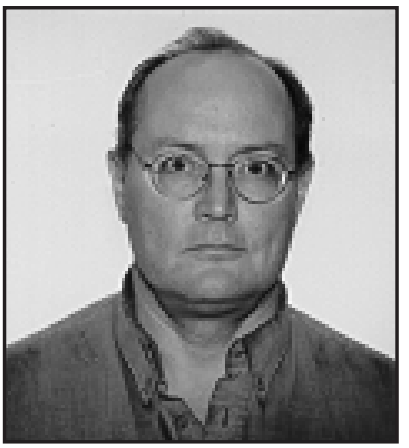

Peter Besseau determine if the Model Forest approach to sustainable forest management, then being pioneered in Canada, had application

\footnotetext{
${ }_{1}^{1}$ Deputy Executive Director, IMFNS, E-mail: PBesseau@idrc.ca

${ }^{2}$ Senior Program Officer, IMFNS

${ }^{3}$ Executive Director, IMFNS

${ }^{4}$ International Development Research Centre, Head Office, International Model Forest Network Secretariat, 250 Albert Street, PO Box: PO Box 8500, Ottawa, Ontario K1G $3 \mathrm{H} 9$

${ }^{5}$ IMFNS is sponsored by the Canadian International Development Agency (CIDA), the International Development Research Centre (IDRC), the Canadian Department of Foreign Affairs and International Trade (DFAIT), and the Canadian Forest Service of Natural Resources Canada (CFS).
}

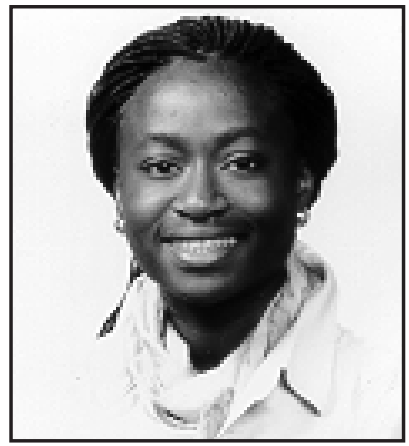

Kafui Dansou

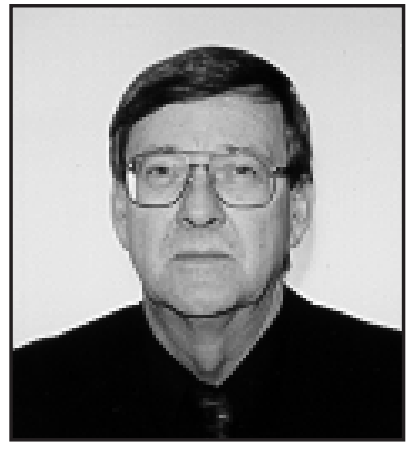

Frederick Johnson outside of the country. The programme initially resulted in the establishment of model forests in Mexico (2) and Russia (1), which were each "twinned" with a Canadian Model Forest. The programme was provided overall strategic direction and support through the IMFN Secretariat, which works to encourage and support the development of existing and new sites. After several years of continuous growth and development, the IMFN now comprises 19 sites in 11 countries (excluding those in Canada, which comprise an additional 11 sites). It is also establishing its first regional network centre, in Latin America, and is looking to develop regional network centres for Asia and Africa. By virtually any yardstick the model forest approach can be mea- 


\section{The International Model Forest Network}

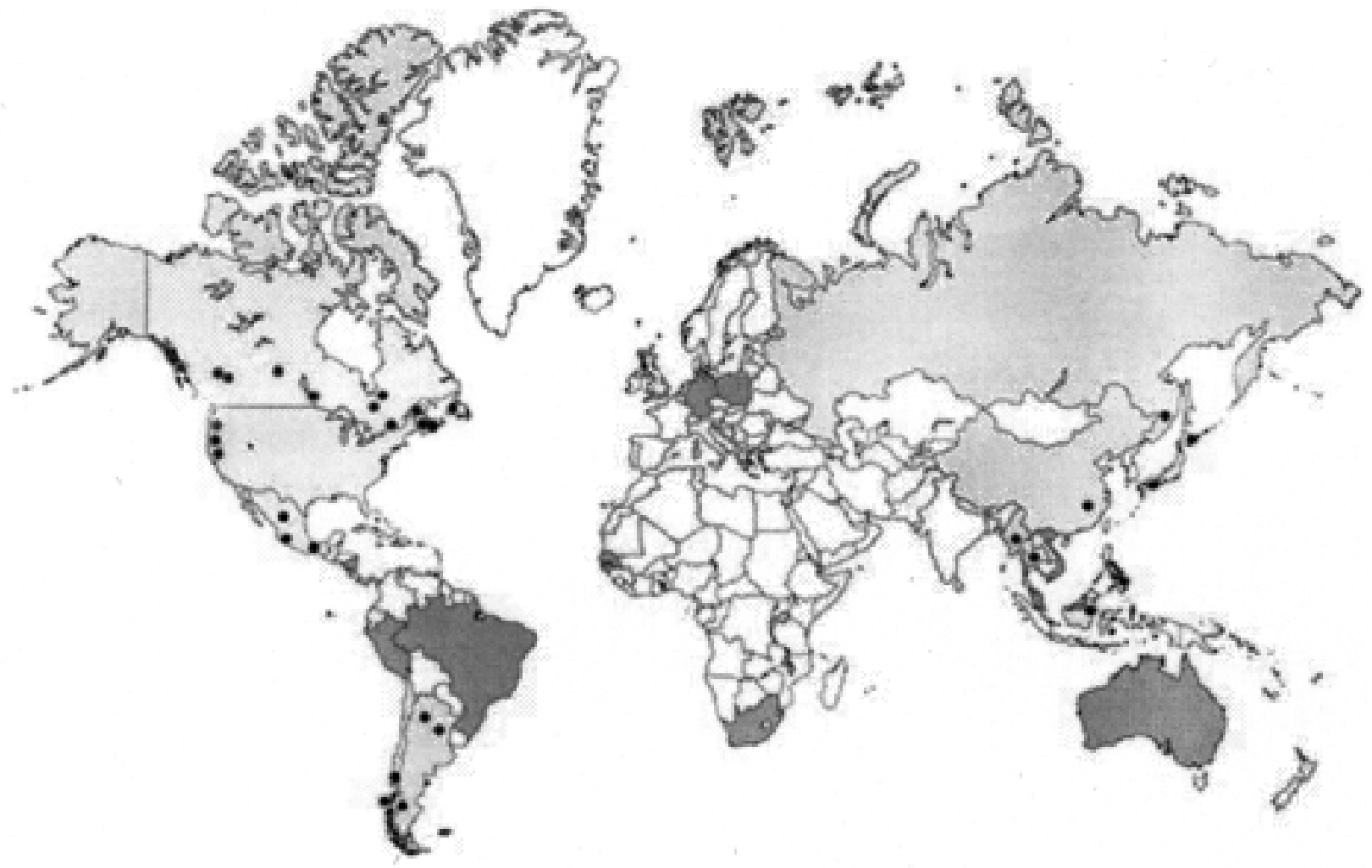

Model Forest Sites (established or in development) - (dots)

Argentina: Formosa, Futaleufú, Jujuy

Canada: McGregor Prince, Foothills, Albert Manitoba, Lake Abitibi, Eastern Ontario, Waswanipi, Bas St-Laurent, Fundy, Western Newfoundland, Nova Forest Alliance

Chile: Chiloé, Alto Malleco

China: Lin' an

Indonesia: Berau

Japan: Ishikari Sorachi, Shimanto-Gawa

Mexico: Calakmul, Chihuahua, Monarch Butterfly

Myanmar: Pauk Khaung

Philippines: Ulot Watershed

Russia: Gassinski

Thailand: Ngao

United States: Cispus, Applegate, Hayfork

Countries expressing interest (shaded areas)

Australia, Brazil, Cuba, Costa Rica, Germany, Malawi, Malaysia, Peru, Dominican Republic, Poland, Senegal, South Africa, Vietnam

As of July 2002

sured as an international success for Canada, and for Model Forest Practitioners at home and abroad.

With the World Summit on Sustainable Development (WSSD) taking place in Johannesburg, South Africa, in September 2003, this "Rio+10" event offers a very appropriate milestone from which to consider the question of what has made the IMFN programme the success it has become. In this paper we will propose that there are several prominent elements of success: the idea itself, its flexibility, the support that has been provided in its development and application, and its ability to leverage substantial additional resource. As practitioners of this approach are well aware, Model Forests have been successful, but not uniformly and not without significant effort and money. As a counterpoint to the several "elements of success" described in this paper we therefore also devote attention to some of the obstacles to and complications of applying the Model Forest approach. The observations that we have drawn in this paper pertain to the experiences of the IMFNS but there are doubtless similarities between these and what has been experienced in the Canadian Model Forest Network (CMFN). 


\section{Model Forests: Reconfiguring an Idea}

For centuries, issues of forest resource management have challenged humankind and its ingenuity. The conflicting demands and interests placed on forest resources coupled with the inherent complexity of the issue have shown that traditional intra-disciplinary approaches are not effective in the long term. The contradiction between the desire to satisfy today's societal demands upon a resource base with the recognition that ensuing changes in ecosystem quality will limit the choices and options of tomorrow's societies often forced discussions to broader fora where different groups were givenor simply took - the opportunity to voice their concerns, present their viewpoints and bring forth new ideas. In response, there have been reactions that range from denial to administrative decree and from decentralization to consultation. There is no shortage of examples of the issue being successfully dealt with but unfortunately, in the context of world experience, these constitute a group of small-scale exceptions to established rules and practices. Certainly, among these exceptions, we could include the world's very large number of community forestry initiatives now well established primarily in the developing world. At a fundamental level what these scattered successes demonstrate is an intuitive recognition that collaboration offers greater and more effective means of responding to the complex issues faced in forest resource management. Indeed, such approaches are also an acknowledgement that multiple shared benefits can be realized when local groups are implicated meaningfully as partners in sustainable management of the resource base.

Espousing this idea of participation, the Model Forest concept emerged in Canada early in the 1990s, as part of Canada's National Forest Strategy. Its arrival coincided, perhaps not so coincidentally, with a period when Canada was itself experiencing unprecedented challenge to traditional approaches to forest planning and management. Much of the public's ire was then targeted against what was perceived as unsustainable management of a major public asset-Canada's heavily forested crown lands-and a closed non-transparent relationship between government and industry. The Model Forest programme was specifically intended to create a forum for open access to all stakeholders to the processes of planning and managing forest landscapes. From the outset, the programme showed that it could attract willing participants to form broad-based partnerships to try an innovative approach to dealing with a major public concern in a practical way.

As noted above, the Model Forest concept was not spontaneously generated by uniquely Canadian circumstances but in fact has a lineage of thought and action that goes back centuries, with close conceptual cousins in the past and present in many parts of the world. The parts of which the Model Forest approach are comprised, in fact, (see list, end of this section) are not particularly unique. We can find some or all of these attributes in forest management objectives the world over: in traditional practices, described in National Forest Programmes globally, called for in virtually all criteria and indicator (C\&I) processes, and included among many others in the Inter-governmental Panel on Forests/Intergovernmental Forum on Forests (IPF/IFF) Proposals for Action. What Canada did, however, was package these parts in a highly innovative and deliberate way with the explicit goal of linking policy objectives to processes and tools for sustainable forest management (SFM) at the field level, and anchored by the principle of inclusive, locally-based partnerships. Although a dynamic link between policy, practice and partnerships has long been proposed and discussed, particularly since the Bruntland Commission Report, there were then and there remain today precious few initiatives that have successfully done this. Canada did this with the Model Forest programme.

So, what specifically was the nature of the Canadian innovation? The Model Forest approach combined the idea of participation with a focal point and operating environment to support constructive and inclusive dialogue leading to specific actions in support of SFM at the field level. Among the impressive results of this amalgam is that it provided a way for an inclusive partnership to develop in a way that was neither threatening to those with power nor intimidating to those without, while_-very importantly_having positive impacts on SFM. More specifically, it proposed a systematic approach to institutionalize participation organized around actual field-level projects that reflected local values and needs and which had high demonstration and learning opportunities. It emphasized the imperative for networking to take place first at the local level, for sharing of views, information, and expertise as a way to articulating SFM fully and as a way to learn, build trust and put in place working relationships at the operational level. It translated recognition of multiple values by promoting and testing integrated resource management on a large working scale, and in ways that were valuable to both the operational and policy levels. Last, but certainly not least, it provided a promising programme through which significant core funding from the Federal government was directed and co-funding was leveraged from other partners over a relatively long period of time (five years initially). This allowed the experiment time and resources to acquire the tools needed, suffer growth pains, learn, adapt, become established, and experience success. This "package" as promoted by the IMFNS is contained within the six minimum attributes that describe what a Model Forest (MF) is:

- based upon an inclusive partnership;

- committed to SFM;

- large enough in scale to incorporate the areas' forest uses and values;

- active in a range of areas that reflect environmental, social, and economic values;

- the MF is organized to ensure full participation of all stakeholders;

- committed to networking at all levels.

Based upon the above, we can conclude at least two things about the acceptance of the MF approach abroad. First, its application outside of Canada has been successful not because the approach represented the introduction of a hardy Canadian exotic, but rather the opposite. In large measure the elements that make up a model forest were already out there-granted, as in Canada, more in principle than in practice — but nonetheless there. What Model Forests represented was a practicable mechanism to apply the shared principle of participation in order to articulate a concrete field-level programme for SFM. Second, the approach was readily accepted because throughout the world the same challenges were/are being faced - that is, it is highly demand-driven. 


\section{Flexibility}

While the idea itself was a strong point in attracting others to consider it, it has been the flexibility of the approach to local circumstances that has allowed it to be adopted so readily. Its originators may not have given consideration to the modalities of the Model Forest's application on a south Philippine Island, for example, or in an intensively farmed rural province of China, but the Model Forest approach has nonetheless proven to be highly applicable and extremely flexible in its ability to respond to local circumstances without compromise to its original objectives and goals. Certainly, there are differences found in form, function, and content from one site to the next; however, these differences are largely of degree rather than of kind, and are reflective of different and often significant social/cultural, political, environmental and economic variables. The important point here is that a coherent, shared foundation is found throughout the network and forms the IMFN's principal pre-condition to exist as a network, for identifying and delivering network services, transfer of technology and knowhow, and a host of other activities designed to support sites and accelerate the introduction of innovative practices for SFM. At the same time, individual Model Forests have the latitude to define SFM in locally relevant terms and create a plan of action that reflects local needs and priorities.

\section{Similarities}

Looking first at similarities, these fall into three relatively narrow categories, all within the context of SFM: partners, management objectives/issues, and tools. Many of the main partner groups are found with relative consistency across the network: the national-level lead is assigned to the Forest Department; other resource-based departments are represented, generally by their local representative, research and academic partners, indigenous communities, industrial logging interests, small businesses, and civic organizations are typically all represented on partnerships. Similarly, the management objectives or issues around which SFM challenges are framed at a given location are largely comprised of a well-known core group. Among several others, these would include forest management practices, biodiversity and water protection and conservation, and sustainable resource-based economic development. Similarly, many of the tools applied to deal with the issues identified by the MF partnership are often globally recognized: development of effective participatory processes, development and application of GIS, defining C\&I and local-level indicators (LLI) of SFM, public outreach and education, and so forth. These three things-partners, issues, and tools-form the bedrock of commonalities that make the network a network, and that make a global community out of individual initiatives as geographically and culturally separate as Chile and China.

Of the three commonalities, it has been primarily the tools that have catalyzed opportunities for innovation and networking, and which will continue to provide the network with multiple opportunities for growth, innovation and technology transfer. It is in this area of tools that the CMFN has provided exceptional input to the IMFN, particularly in areas such as partnership building and LLI, and where there will continue to be significant opportunities to share Canadian skills and know-how.

\section{Differences}

The Model Forest approach has been applied abroad with full respect to local circumstances, traditions, laws, and customs but still within the core group of attributes that define a Model Forest. As a result, Model Forests have taken locally flavoured approaches to development. For example, it has affected the pace at which the partnership is built (faster in the Philippines, slower and more cautiously in Thailand), the core partner group (heavy representation by government in Russia, very broad-based in China, and with strong church leadership in Chile), and the priorities (forest science and economic development in Russia, conflict resolution and alternative livelihood opportunities in Mexico, and creating an effective neutral forum to develop consensus on regional development in Indonesia). Overall, however, the most important innovation encountered in the application of the Model Forest approach abroad, and its most significant difference from Canadian experience, has been its clear identification by developing country practitioners as a development tool for forest-based communities-not at the expense or instead of SFM, but in the context of it.

This evolution has taken place largely because the Model Forest approach is not directive in nature, but rather it sets in place an operational environment in which the choices and trade-offs involved in work toward SMF can be vetted by stakeholders and then acted upon. Not surprisingly, issues of participatory processes and economic opportunity have therefore featured among the most important for these model forests.

\section{Participatory Processes}

Participation in developing country Model Forests is perhaps more broad-based than what would be found in Canada, drawing large numbers of individual farmers, entrepreneurs and concerned citizens to participate directly in such discussions for the first time. Developing country Model Forests place a great deal of energy into the business of partnership building, and it tends to be more cautious (because it is less familiar) and yet a more ambitious undertaking (because the consequences are potentially more profound) than might be the case, for example, in Canada. In terms of supporting the development of civil society in many Model Forests, be it the Berau in Indonesia, Chihuahua in Mexico, or the Ngao in Thailand, one of the most important contributions that a Model Forest has made has been to provide a neutral, non-threatening, and constructive forum for stakeholders interaction. In fact, in many instances the Model Forest forum has represented the only mechanism through which these various stakeholders interact constructively as a group.

\section{SFM Dividend}

In a similar vein, while developed country Model Forests tend to have well-developed infrastructure and economies, circumstances in developing countries typically include subsistence farming, insecure land tenure, poor infrastructure, and populations deriving some or all of their material needs directly from the forest. In addition, many local communities often lack the capacity to effectively participate in resource management discussions - even if there is a seat at the Model Forest discussion table for them. In these circumstances, the Model Forest often faces more pressing community sustenance challenges and it has played a very different role from what would typically be found in developed countries. Again, this has not been to the 
exclusion of the technical aspects of $\mathrm{SFM}^{6}$, but the imperative for an SFM dividend in the form of improved material and social well-being predominates and strongly influences the strategies and work plans adopted by such model forests. In the case of Russia's Gassinski Model forest, for example, while it had a comprehensive programme of action, including improved forest practices, forest fire control and biodiversity protection, its greatest impact has been in the area of identifying and putting into operation a sustainable economic development strategy for the area's many small, forest-dependent communities. Among other accomplishments, it has resulted in the creation of value-added wood processing industries, in one case generating nearly full employment in a Nanai (indigenous people's) village. It has also resulted in the establishment of harvesting norms for non-timber forest products (NTFP), and new jobs in their collection and processing.

The Model Forest approach can accommodate these various differences in partnership, pace, and priority without compromising its fundamentals precisely because it is an approach or process, rather than a project.

\section{Leveraging and Pooling Resources}

All Model Forests experience inadequate revenues relative to their stated needs and desired programme of actions. In developing countries the competition for dollars is acute, as are the needs, and so the need to pool and leverage resources is an absolute. The advantage of the Model Forest approach in this regard is that its interdisciplinary collaborative underpinnings encourage pooling of resources as an operational objective from the outset and beginning at the community level. At the local level most Model Forests have discovered that the resources available, when pooled, are considerably larger than previously understood to be. As such, one of the first dividends of partnership is not leveraging of international donor support but leveraging within one's own partnership, from business skills to facilities and from contacts with influential people to specific technical expertise. Related to this, and perhaps of equal importance to the success of leveraging has been the fact that Model Forests are seen as being well-supported platforms (national level support, technical support, etc.), with dedicated resources and a management capacity. As such, they are viewed by donors as being low-risk and having a high potential for success.

Leveraging has also included working with other Model Forests. This has certainly been the case in the Canadian Network (LLI, Communications, and Enhanced Aboriginal Involvement). Outside of Canada, the Regional Model Forest Project (RMFP) in South East Asia led by the Food and Agriculture Organization of the United Nations (FAO)-Bangkok, has been an excellent example of pooling resources and collaboratively working to address commonly held management issues across four quite diverse countries. This has included joint work in bamboo pro-

\footnotetext{
${ }^{6}$ For example, the Government of Japan/FAO-led Regional Model Forest Project in South East Asia is active in supporting the introduction and demonstration of best practices for Sustainable Forest Management through four model forests (China, Philippines, Myanmar, and Thailand). In addition to creating unique partnerships for SFM, the four countries have also worked together under this project to undertake policy gap analyses from the field level, visà-vis SFM, and have worked together to introduce and strongly advance Local Level Indicators (LLI) for each site.
}

duction, eco-tourism development, C\&I and LLI, the development of participatory processes, and resource expansion.

In Chile's Chiloé Model Forest, the MF approach has been very enthusiastically adopted and continues to provide multiple benefits to its partnership. It has focused its energies and resources on a number of priority areas including biodiversity conservation, improving local living conditions, indigenous knowledge, traditional crafts, eco-tourism, improving export markets for the islands products, and education. The work of the partnership has generated a very impressive 3:1 leveraging of financial resources against the initial contribution of the national government in addition to yet-unvalued technical inputs.

Of course, the specific nature of the IMFN is leveraging through networking, exchanging and learning about SFM by virtue of being part of a global community of efforts with shared goals, and accelerating the introduction of innovative and better practices through network affiliation. While the IMFNS is not a grant-making entity, it has facilitated significant on-going transfer of know-how and technology, donor ties, and targeted direct funding.

\section{Support}

If the Model Forest concept itself represents one of Canada's main contributions to SFM internationally over the past several years, then its very concrete support and encouragement of Model Forest development abroad represents the equally valuable other side of the same coin. Indeed, good as the idea may be, it would not have travelled as well as it has without resources and highly qualified and directed support.

Since the international programme was announced in 1992 , the four sponsoring Canadian agencies have provided in excess of $\$ 12$ million in financial contributions, roughly twothirds of which came from Canada's Green Plan through DFAIT. Most of these funds were contributed to the original three twinning arrangements (from 1994-1998) between Canadian, Mexican and Russian model forests. It also provided support to the IMFN Secretariat allowing it to build a programme to lead the international effort from its headquarters at IDRC, in Ottawa. Over time CIDA has become an increasingly important financial supporter of the international programme, both to core support for the Secretariat, and in support of expanding the network, as is now seen from its support of the Latin American Regional Model Forest Centre.

The IMFN's strong financial support has been matched with strong technical and professional support from the Canadian Model Forest Network (CMFN) and its Secretariat at the Canadian Forest Service and has undoubtedly been one of the main "elements of success" for the IMFN. From the outset, the CMFN was rightly looked upon as the pioneer in model forestry and has been called upon innumerable times to assist on virtually all aspects of model forest development and operation in international sites. To their credit and that of their partners, Canadian Model Forests have invariably responded with enthusiasm to these frequent demands. Indeed, Canadian Model Forest practitioners have been among the IMFN's biggest supporters, demonstrating in practice the spirit of "networking" by providing a steady stream of experts, guidance, technology, and documentation to support virtually every site in the international network. 
With the exception of the initial "twinning" relationships, through which three Canadian Model Forests were selected to assist in the development of Model Forests in Mexico and Russia, the delivery of Canadian Model Forest expertise has followed fairly traditional routes: hosting missions, participating in missions abroad, sending experts to work at a model forest site, participating in workshops and symposia, and providing training, for example. The CMFN, with the encouragement of its Secretariat, has also had an "open door" policy to the international MF sites which has allowed IMFN representatives to attend many of the CMFN's operational and strategic planning meetings. Still other Canadian Model Forests have taken less traditional routes, individually exploring opportunities for linkage with sites in the IMFN, such as the McGregor MF's with Russia's Gassinski MF, and Manitoba MF's with the Mariposa Monarcha MF, in Mexico. Lastly, the technical and other documentation produced by individual Model Forests and the CMFN Secretariat have been highly valued resources that continue to provide an important link among all sites within the Network.

Two observations are worthy of particular attention in describing and characterizing the support that has been provided by the CMFN to the IMFN. First, is the remarkable breadth of activities that have been undertaken. These range from work on protected areas to student exchanges, from links between indigenous peoples to business development, from GIS applications to partnership maintenance, and a host of others. In short, the IMFN has had available to it a uniquely comprehensive and experienced network of some 400 individual organizations and experts, from coast to coast through the CMFN. Second, most of the Canadian experts who have been called upon to help, either in Canada or by travelling to sites or events outside of Canada, have been locally-based experts from the Model Forests themselves, and from virtually every region of the country. This peer group interaction between Canadian and non-Canadian Model Foresters has been enriching for Canadian participants and very important for Model Forest practitioners outside of Canada, who derive consistent benefits from working with Canadians who are engaged through their Model Forests in "hands-on" activities related to SFM at the field level.

\section{International Support}

IMFN members have also benefited greatly from substantial parallel contributions of cash and expertise from donors and partners outside of Canada. For the period from 1995 to 2001, IMFN members registered nearly $\$ 7$ million in such contributions in cash and in kind. This includes Global Environment Facility (GEF) support to the Chiloe Model Forests, the support of the government of Japan for a series of international conferences on Model Forests, and for the Regional Model Forest Project for South East Asia (in excess of $\$ 3$ million) and, of course, the matching contributions provided by host governments. In recent years, the FAO has been a very strong and high profile advocate of the Model Forest development. Indeed, following the 2001 meeting of the Committee on Forestry (COFO) in Rome, FAO became mandated to support and encourage the development of Model Forests. Additionally, as the delivery agent for the four RMFP Model Forests in Asia FAO has developed considerable expertise in Model Forest development. Notable as well is the growing role of the United Nations Development Programme (UNDP), which, among other actions, will be the host of the Regional Model Forest Centre for Latin America and the Caribbean (RMFC-LAC), in Santiago Chile. Other parallel contributions have been made by many agencies directly to Model Forests, including WWF, the EU, AusAid, and USDA Forest Service.

\section{Caveats}

As encouraging as the approach is, we know from experience that Model Forests develop at different rates, with some making it appear effortless and others struggling from the outset. We have seen that a poorly chosen site for example, and/or soft institutional support can call into question the wisdom of beginning at all. We have also learned from the dozens of countries that have investigated it that the Model Forest approach is not universally suitable or applicable to all situations, and that there are a range of other approaches available. In addition, what Model Forests do, vis-à-vis SFM, may not be what some want or need. So, while we can readily acknowledge that the approach is innovative, flexible, and adaptable, we must also acknowledge that it is not endlessly so and that it is also a demanding, long-term, and fairly complex venture.

For those who decide to adopt the Model Forest approach there are a number of things that time and experience have shown us that Model Forests need: these include money, capable and energetic advocates, unambiguous national level support, clear objectives, and a generous amount of time. Arguably, just about any undertaking could generate the same list of needed inputs; however, in the case of the Model Forest the one factor that most influences the others is time. Because we are involved in developing and nurturing a process - rather than delivering a project - and one that is considerably longer than a traditional three- or five-year project, all of the inputs need to be understood and committed with a rigour of design and depth of commitment that will take them beyond typical project time horizons. Thus, political support from national and other levels of government needs to be not simply supportive but supportive for reasons $\mathrm{x}, \mathrm{y}$, and $\mathrm{z}$, for reasons that will generate strong, tangible, and ongoing support, and for far-sighted, strategic reasons that reach beyond traditional project time horizons.

This need for long-term commitment is reflected in the intensity of input and length of time that it typically takes to establish a Model Forest: usually at least one or two years and a good many workshops, meetings, and demands for documentation. The time involved is an indicator of the steepness in the learning curve and reflects the fact that in learning new things we are also "unlearning" others. For example, a great deal of time and effort is typically expended simply in coming to understand the Model Forest as a process rather than as a project and in broadening the measures according to which we claim progress and success. And it also takes time for partners to appreciate perspectives held by others in the emerging Model Forest partnership instead of simply maintaining one's professionally bordered views. It is also indicative of the time and effort needed to stitch together a functioning core partnership where none may have existed before and to the effort necessary to marshal the political, financial, and technical resources to make it all work.

The issue of site selection is also key. Given the high demands placed upon a Model Forest the site chosen will need to meet a number of criteria. Indeed, if financial or tech- 
nical resources are not adequate, it is even more important that sites be chosen in order to assure that their starting point and opportunities for growth are advantageous. In early work to detail terms of reference for the Regional Model Forest Project for South East Asia, IMFNS and FAO developed an unofficial table of criteria for site selection for Model Forests to aid countries in site selection, composed of necessary criteria and desired elements. These included issues of physical accessibility, balance of national, regional, and local relevancies, existing facilities, databases and infrastructure, and variety and commitment of stakeholders within the region.

\section{Conclusions}

The Model Forest concept is presently well evolved from its origins. It began in Canada to forge better partnerships for SFM and for better integration of the various disciplines and interests associated with SFM. It has retained these goals but has further evolved in its international incarnation into an important development tool. Within the context of SFM, its broad partnerships, diverse resource base, neutrality, and focus on an issue of obvious shared interest continue to allow practitioners to build trust and effective horizontal ties among stakeholders at the fieldlevel and to make positive gains in areas such as conflict mediation, good governance, poverty alleviation, and local capacity, particularly among the rural poor.

With the launch of the CMFN's third five-year phase, Canada will continue to be looked upon as a leader in this area and looked upon to share its experiences and know-how. As the IMFN has grown, its various sites have also increasingly interacted with other SFM-related initiatives around the globe and there are many emerging opportunities for collaboration and exchange. Some of these, for example, the International Tropical Timber Organization's (ITTO) Demonstration Areas, the Center for International Forestry Research's (CIFOR) work in Adaptive Collaborative Management, FAO's Demonstration Forests, UNDP's programmes to find working solutions to rural poverty in the developing world, have much in common with Model Forest. As the IMFN grows it should seek out alliances and collaborative opportunities with like-minded initiatives in order to reinforce and accelerate the introduction of best practices at the field level. Jointly, there are many opportunities in the future for such action. Among the many things that Model Forests have to offer is their large scale of operation, which has resulted in the creation of unique well-supported platforms for undertaking a range of pure and applied research projects. Perhaps more importantly, the IMFN experience in building partnerships may be of greatest value. After all, the Model Forests modus operandi is to tackle one of the thorniest issues in SFM head-on-to deal with the so-called intangibles of human, multi-stakeholder interaction at the operational level, in real terms. These experiences — success and failure alikeoffer important lessons and should be more fully available to the broader SFM community. 